\title{
Factor Related to Nutritional Status of Children with Disability Living in Dhaka City, Bangladesh
}

\section{Md Harun-Or-Rashid ${ }^{1 *}$, Abul Hasnat Mohiuddin², Omar Faruque ${ }^{3}$, Bijoya Sarkar ${ }^{4}$, Kakoli Alamgir ${ }^{5}$, Abu Yousuf ${ }^{6}$ and Shamim Reza ${ }^{7}$}

${ }^{1}$ Consultant (Physiotherapy), New Life Trauma Centre, Rampura, Dhaka, Bangladesh

${ }^{2}$ Assistant Professor and Head of Physiotherapy Department, Dhaka College of Medical and Technology, Mohammadpur, Dhaka, Bangladesh and Consultant

(Physiotherapy), Islami Bank Central Hospital Kakrail, Dhaka, Bangladesh

${ }^{3}$ Clinical Physiotherapist, Gono Shasthaya Kendra Hospital, Cox's Bazar,

Bangladesh

${ }^{4}$ Physiotherapist, Gono Shasthaya Medical College Hospital, Mirzanagar, Savar,

Dhaka, Bangladesh

${ }^{5}$ Chief Clinical Physiotherapist, Bondhon Hospital and Diagnostic Centre, Jashore, Bangladesh

${ }^{6}$ Physiotherapist, Jobed Ali Memorial Hospital Pvt. Ltd, Araihazar, Narayangonj,

Bangladesh

${ }^{7}$ Chief Physiotherapist, Shimla Hospital, Pabna, Bangladesh

*Corresponding Author: Md Harun-Or-Rashid, Consultant (Physiotherapy), New

Life Trauma Centre, Rampura, Dhaka, Bangladesh.
Received: May 19, 2021

Published: June 02, 021

(C) All rights are reserved by Md Harun

-Or-Rashid., et al.

\section{Abstract}

Purpose: To assess the nutritional status and nutritional related knowledge of children or their caregiver of CWD in Dhaka city.

Objectives: To assess the anthropometric measurement by BMI, WAZ, HAZ of the respondents, To assess the nutrition related knowledge of the children or their caregivers of the respondents, To appraise the food frequency pattern of the participants, To find out socio-demographic (age, gender, family type, living area, educational status) characteristics of CWD Parents.

Methodology: Children with neurodevelopment disorders living in Dhaka city. CWD (neurodevelopment disability like as Autism, CP, ID and Down syndrome) living in Eskatan and SWID Bangladesh between September 2020 to March 2021. The instruments used included direct interview, a standard questionnaire and Knowledge of nutrition and food frequency pattern. Data were numerically coded and captured in Excel, using an SPSS 22.0 version.

Results: The findings of the study provide a baseline of information about find out nutritional status and FCS disabled child in Bangladesh the study found that mean age of the participant was 9.98 (SD \pm 1.62 ) years and most of the participants were above 5 years. The youngest participants in this study were 7 years old and oldest participants were 12 years old. In this study, this study showed that male caregivers participants were highest rate that was $58.6 \%(n=51)$. Female caregivers participant were rate that was $41.4 \%(n=36)$ with males attended more than females, in this study showed >10000 BDT range participants were highest rate 
( $\mathrm{n}=36$ ) with males attended more than females, in this study showed $>10000$ BDT range participants were highest rate that was $62.1 \%(n=54)$. Primary passed participants were highest rate that was $34.5 \%(n=30)$. More degree passed participant were second highest rate that was $31 \%(n=27)$. According to our findings, knowledge about nutrition of the participants showed that no participants were highest rate that was 39.1\% $(n=34)$. Yes participant second highest were rate that was $34.5 \%(n=30)$ and not sure participants were $26.4 \%(n=23)$. Knowledge about nutrition components of the participants. This study showed that yes participants were highest rate that was $41.4 \%(n=36)$. No participant second highest were rate that was $29.9 \%(n=26)$ and not sure participants were $28.7 \%(\mathrm{n}=25)$.

Keywords: BMI; Cerebral Palsy; Knowledge; Neurodevelopment Disorders and Nutritional Status

\section{Abbreviations}

BRC: Bangladesh Rehabilitation Council; CWD: Children with Disability; DPOs: Disabled People's Organizations; FAO: Food agriculture organization; KAP: Knowledge, Attitudes and Practices; MDGs: Millennium Development Goals; MOH: Ministry of Health; PWD: Person with Disabilities; RNDA: Rapid Neurodevelopment Assessment; UNCRPD: UN Convention on the Rights of Persons with Disabilities; UNICEF: United Nations Children's Fund; WHO: World Health Organization

\section{Introduction}

Disability is defined as the interaction between persons with disabilities and the attitudinal and environmental barriers that prevents their effective participation in the society on an equal basis with the persons without disabilities [3].

Persons with Disabilities (PWD) are susceptible to nutritional impairment which eventually results in abnormal body composition and growth failure. The impact of malnutrition as the most frequent cause of growth impairment, particularly among the severely affected people, raised major public concerns International studies have been documented that under-nutrition was found in almost $50 \%$ of children with cerebral palsy [7].

Persons with disabilities (PWD) are individuals who experience long term physical, mental, intellectual or sensory disablement leading to barriers that impede them from full and effective participation in society. Population with disabilities accounts for a significant portion of world population. More than one billion people in the world (15\% of the global population) are having some forms of disability [20] World Report on Disability. Geneva, Switzerland) and, approximately $20 \%$ of them experience substantial difficulties in functioning. In Bangladesh, an estimated 2.8 million people live with various forms of disability. More than 850 thousand children below 15 years ( $10 \%$ of the Bangladesh children population) have a disability and at least one third of them are severe.

In spite of robust healthcare strategies and disability rights movement, PWD are still prevalent to poor health. Malnutrition, either under-nutrition or over-nutrition, is evident among PWD. Among children and adolescents with disabilities, underweight prevalence in a range of $5 \%$ to $30 \%$ had been recorded in France (5.4\%) [9], Chile (10.8\%) [17] and Taiwan [6]. Besides, more than one third of these children were also found to be overweight or obese, as reported in the United Kingdom (33\%) [13], Taiwan (37.7\%), Chile (38.7\%) and the United States (55.1\%). In addition, Bhaumik., et al. (2008), Melville., et al. (2007) and Wong (2011) presented that half to two-third of the adult population with disabilities in the United Kingdom and Hong Kong were suffering from this double burden of malnutrition $(69.7 \%, 67.3 \%$ and $52.7 \%$, respectively).

The Encuesta Nacional De La Situacion Nutricional En Colombia (ENSIN, 2015) reported $10.8 \%$ of infants and children (0 to 5 years old) with short tall, a measure higher than the goal of $8 \%$ established in the Millennium Development Goals (MDGs); there was expected to reduce acute malnutrition to $1.3 \%$ but only $2.3 \%$ was reached for the same segment of the population. Preventing acute malnutrition means to reduce the risk of infant mortality, while preventing chronic malnutrition can reduce the risk of permanent disability. The achievement of these two purposes is considered possible through food security programs, applied preferentially in the first thousand days of development, counted from conception. Consolidate these processes, improves the perspective of perfect neurological development and, integral development of the future people, as a generating base of social transformations [12].

During the first periods of childhood, malnutrition has a character of severity which significantly affects the consolidation of brain 
structures, whose damage can lead to metabolic and functional changes irreversible [8]. The problem is not only a deficiency phenomenon; its determinants are located in a social, economic and cultural environment that must necessarily be considered when designing health interventions [18].

Colombian government, in the Plan Nacional de Desarrollo 2006 - 2010, has endeavored to prioritize the design and implementation of a food and nutrition security policy, as a strategy aimed at achieving, in principle, guarantee of fundamental rights, especially of infants; jointly with the improvement of economic and social environments, increasing the volume and capacity of human capital, establishing regional conditions of development and peace, strengthening of government institutions and reducing poverty. To this goal, social promotion interventions and social risk management have been planned as a strategy [14].

Because these reasons, it is considered that, in addition to the physical availability of nutrients, it is essential that communities have an acceptable level of knowledge about the composition and importance of nutrition characteristics of food available in their environment; improve attitudes towards hygiene, self-care, good health and daily practices leading to a healthy diet [15].

Various experiences in which the focus of public policies is aimed to the development of designed interventions, from the results of anthropometric diagnoses, without link correlation with educational, social and cultural determinants, have been little or nothing effective. Consequently, for several years some institutions such as FAO, WHO, UNICEF, have been developing instruments that allow quantifying with high precision, Knowledge closely linked to nutrition, in order to optimize the applicability, validity, standardization and comparability between different studies. The present study, aims to determine the possible association between the nutritional status of children under two years and the Knowledge of adult caregivers, including dietary diversity according with the food groups.

Whereas children are clearly an important period in human development, it has often failed to receive the attention given to earlier periods in childhood with regard to health-related uses and interpretations of anthropometry. Historically, the rapid changes in somatic growth in children, the problems of dealing with variation in maturation, and the difficulties involved in separating normal variations from those associated with health risks have all discouraged researchers from developing a body of knowledge about children anthropometry that would link it directly to health deter- minants and outcomes [19]. Knowledge related survey data are essential to help plan, implement and evaluate ACSM (Advocacy, communication and social mobilization) work [11]. A Knowledge survey gathers information about what respondents know about adolescent mother's nutrition, what they think about disease or about the health system, and what they actually do with regard to seeking care or taking other action [4]. Knowledge surveys can identify knowledge gaps, cultural beliefs, or behavioral patterns that may facilitate understanding and action. To some extent, they can identify factors influencing behavior that are not known to most people, reasons for their attitudes, and how and why people practice certain health behaviors [5]. Knowledge surveys may be used to identify needs, problems and barriers in program delivery, as well as solutions for improving quality and accessibility of services. The data collected enable program managers to set adolescent mother's nutrition program priorities, to estimate resources required for various activities, to select the most effective communication channels and messages, to establish baseline levels and measure change that results from interventions and for advocacy and the fundamental information needed to make strategic decisions.

According to reports of BDHS 2014, nearly 113 girls of age between 15-19 years have begun childbearing and the percentage is $31 \%$. The consequences of early childbearing are felt by society as well as the families directly affected. The incidence of births to very young women, both married and unmarried is growing; each year approximately 13 million children are born to young mothers. The percentage of live births to mothers under the age of 20 ranges from $20 \%$ in some African and Caribbean countries, to $10-15 \%$ in many Latin American countries, 5-10\% in Asia and 1\% in Japan.

Early childbirth is especially dangerous for adolescents and their infants. Compared to women between the ages of 20-35, pregnant women under 20 are at a greater risk for death and disease including bleeding during pregnancy, toxemia, hemorrhage, prolonged and difficult labor, severe anemia, and disability. Lifelong social and economic disadvantages may be a consequence of teenage birth. Teen mothers tend to have larger completed family sizes, shorter birth intervals resulting in both poorer health status for the family, and a more severe level of poverty. The children also suffer; teen's mothers have a higher incidence of low birth weight infants which is associated with birth injuries, serious childhood illness, and mental and physical disabilities [16]. Hence the young mother's nutritional status is very important. 
Nutrition influences growth and development throughout infancy, childhood and adolescence; it is, however, during the period of adolescence that nutrient needs are the greatest [10]. About 1200 million adolescents in the world's and about $19 \%$ of the total population face a series of serious nutritional challenges in developing country [1]. during shortage of food, most families give more attention that babies are well nourished rather adolescent. Inadequate diet can delay or impair healthy development. Stunting can occur in childhood or during adolescence. In some cultures, girls are fed last and fed least. In girls, poor nutrition can delay puberty and lead to the development of a small pelvis [2]. Poor nutrition starts before birth, and generally continues into adolescence and adult life and can span generations. Chronically malnourished girls are more likely to remain undernourished during adolescence and adulthood, and when pregnant. They are more likely to deliver low birth-weight babies.

\section{Rationale/Justification of the Study}

- Present Knowledge study data are essential to help plan, implement and evaluate nutritional planning and intervention work. This Knowledge of children or care givers survey gathers information about what respondents know about children with disabilities nutritional status, what they think about the health system and what they actually do with regard to seeking care or taking other action. This study can identify knowledge gaps, cultural beliefs, or behavioral patterns that may facilitate understanding and action.

- Teenager period is one of the most vital building periods in human life. Teenagers go through drastic physical and hormonal change. To advice prevent complication of nutritional any kinds of things.

- Malnutrition among children with disabilities is a serious public health and complex problem in developing countries like Bangladesh. In Bangladesh there is a very few study conducted on CWD.

- Poor nutrition is the single most important threat to the world's health. Assessing the nutritional status will enable to assess the nutritional need of CWD and their lack of knowledge and malpractice.

\section{Materials and Methods \\ Conceptual framework}

Nutrition is a fundamental pillar of human life, health and development throughout the entire life span. In our country children with disabilities are more likely to suffer from nutritional deficiencies than others, for reasons including low social status, poverty and lack of proper nutritional knowledge. Nutrition related Knowledge of CWD (neurodevelopment disorders like as Autism, CP, Down syndrome, and ID) in Dhaka city.

\section{Study objectives}

General objective

To assess the nutritional status and nutritional related knowledge of children or their caregiver of CWD in Dhaka city.

\section{Specific objective}

- To assess the anthropometric measurement by BMI, WAZ, HAZ of the respondents.

- To assess the nutrition related knowledge of the children or their caregivers of the respondents.

- To appraise the food frequency pattern of the participants.

- To find out socio-demographic (age, gender, family type, living area, educational status) characteristics of CWD Parents.

Study design

Cross-sectional.

Target population and sample population

Children with neurodevelopment disorders living in Dhaka city. CWD (neurodevelopment disability like as Autism, CP, ID and Down syndrome) living in Eskatan and SWID Bangladesh between September 2020 to March 2021.

Study site and area

SWID Bangladesh (NGO) at Dhaka city, Bangladesh.

\section{Study period}

September 2020 to March 2021.

\section{Sample size}

The actual sample size for this study was calculated as 384 , but as the study performed as a part of academic research project and there were some limitation, so that 87 samples (51 male and 36 female) was taken as the sample of this study from SWID Bangladesh, Eskatan at Dhaka.

\section{Inclusion criteria}

- Age limitation 7 - 12 years.

- Male and female are included.

- Children with disabilities especially neurodevelopment disability as Autism, CP, ID and Down syndrome. 


\section{Exclusion criteria}

- Unstable medical conditions.

- Mentally ill.

\section{Sampling technique}

A sample was selected using simple random sampling method.

\section{Data collection tools}

Demographic information chart were used as data collection and also use as Anthropometry measurement (height, weight, BMI), nutritional related (KAP) and food frequency questionnaire. In that time some other necessary materials were used like Papers, Pen, Pencil, file, Computer and pen drive.

\section{Data management and analysis plan}

Data collected through questionnaire. Collected data was coded rightly and put on to entry by using suitable data entry software. Data analysis was done by SPSS version 22 and quantitative statistics and calculated as percentages and presented by using table, bar graph, pie charts etc. Microsoft office Excel 2013 was used to decorating the bar graph. Questions were asked according to the English format. Face to face interviews were also effective to describe characteristics of a population.

Quality control and quality assurance

The data enumerators were trained and tools were field tested for ensuring the consistency of data. For quality assurance $15 \%$ of the total samples were cross checked by the supervisor.

\section{Ethical consideration}

Ethical clearance was taken from the Asian Institute of Disability and Development (AIDD). Informed written consent (explaining objectives and methods of the study, confidential handling of personal information their rights to withdraw/not responding and voluntary nature of participation) were taken from each of the participants.

\section{Limitation of the study}

Expected sample size was more than 384 for this study but due to resource constrain just 87 samples was taken which is very small to generalize the result for the wider population. With regard to the questionnaires used, ethical considerations and lengthy questionnaire led to researcher using a single items measurement procedure that placed limitation on this finding. The questionnaires took approximately 10 minutes to complete its interviewing.

\section{Expected outcomes}

This study will assess the food frequency intake pattern and nutritional status of the children with disabilities. The findings will possibly help identifying the plausible relation between nutritional related knowledge, attitude, practice and nutritional status of children with disabilities in Dhaka city.

\section{Results and Discussion}

\section{Age of the participants}

In this research, researcher shows that the mean age of the participant was 9.98 years (SD \pm 1.628 ). The respondents age of participant minimum 7 years and maximum 12 years. The range of years 5 (Figure 1).

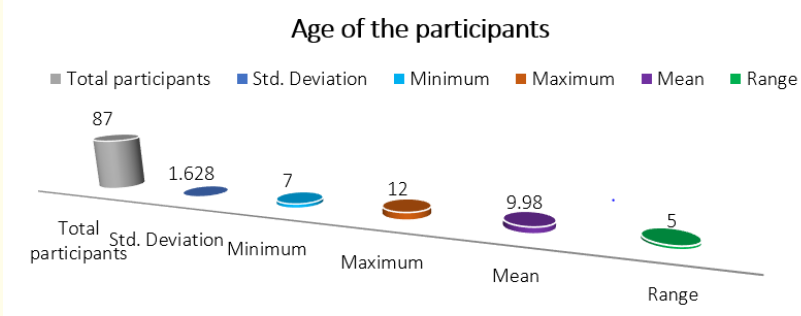

Figure 1: Age of participants.

\section{Educational category of caregivers}

This figure showed that primary passed participants were highest rate that was $34.5 \%(n=30)$. More degree passed participant were second highest rate that was $31 \%(n=27)$. HSC Participants were $19.5 \%(n=17)$, secondary participants were $11.5 \%(n=10)$ and none participants were $3.4 \%(n=3)$ (Figure 2).

\section{Educational status of caregivers}

$$
\text { - Frequency } 1 \text { Percentage }
$$

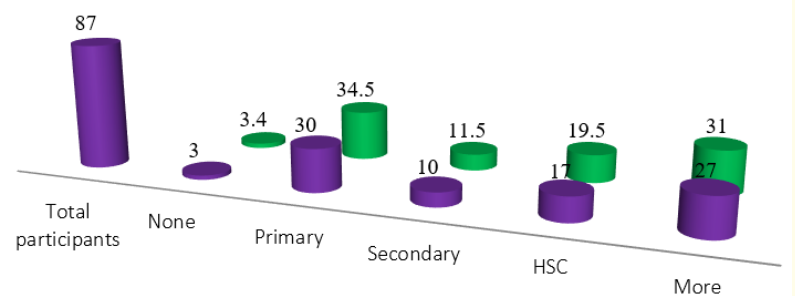

Figure 2: Educational categories of caregivers. 
Monthly total family incomes of parents

This figure showed that $>10000$ BDT range participants were highest rate that was $62.1 \%(\mathrm{n}=54) .7000-10000$ BDT participant were second highest rate that was $19.5 \%(n=17) .5000-7000$ BDT range were $13.8 \%(n=12)$ and $>5000$ BDT range were $4.6 \%(n=$ 4) (Figure 3).

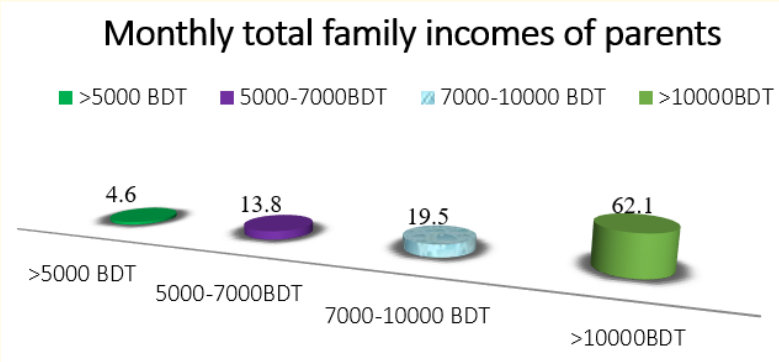

Figure 3: Monthly total family incomes of parents.

Total family members of the participants

This figure showed that four range participants were highest rate that was $60.9 \%(n=53)$. Three and more than four participant were second highest rate that was $16.1 \%(n=28)$. More than six range were $4.6 \%(n=4)$ and more than eight range were $2.3 \%(n$ $=2$ ) (Figure 4).

Total family members of the participants

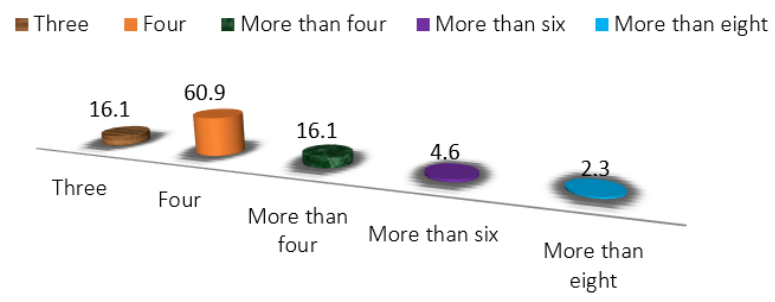

Figure 4: Total family members of the participants.

\section{Types of house the participants}

This figure showed that paka house participants were highest rate that was $71.3 \%(n=62)$. Kacha household participant were second highest rate that was $17.2 \%(n=15)$. Tin shed participants were $11.5 \%(n=10)$ (Figure 5).

\section{Types of house}

- Kacha $\square$ Paka Tin sheed

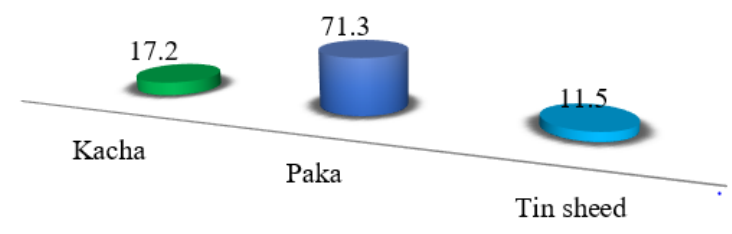

Figure 5: Types of house the participants.

\section{Anthropometry \\ Height of the participants}

This figure showed that minimum height of the participants was that was $120 \mathrm{CM}$ and maximum height of the participants 151 CM. Range 37 (Figure 6).

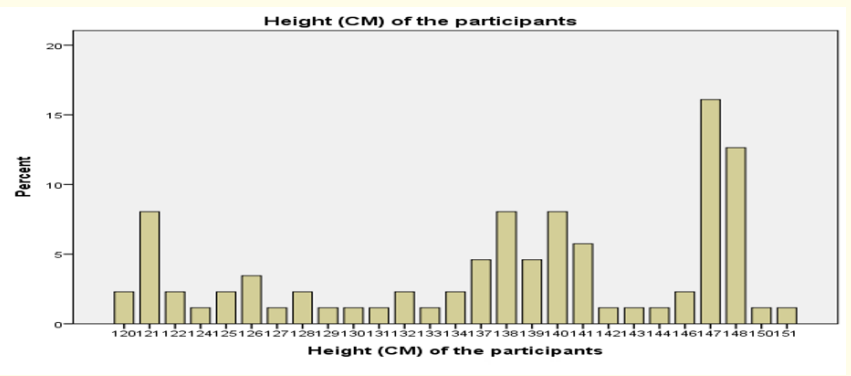

Figure 6: Height of the participants.

\section{Weight of the participants}

This figure showed that minimum weight of the participants was that was $21 \mathrm{~kg}$ and maximum weight of the participants $49 \mathrm{~kg}$. Range 28 (Figure 7).

\section{Nutrition related knowledge}

Knowledge about nutrition of the participants

This table showed that no participants were highest rate that was $39.1 \%(n=34)$. Yes participant second highest were rate that was $34.5 \%(n=30)$ and not sure participants were $26.4 \%(n=23)$ (Figure 8). 


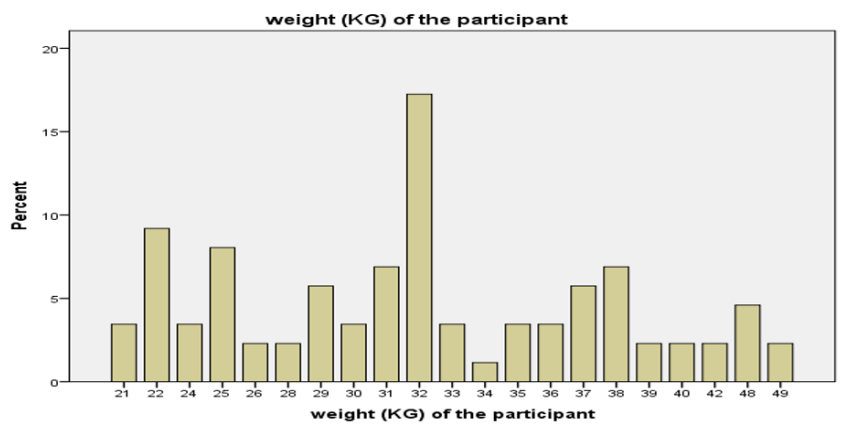

Figure 7: Weight of the participants.

knowledge about nutrition of the participants

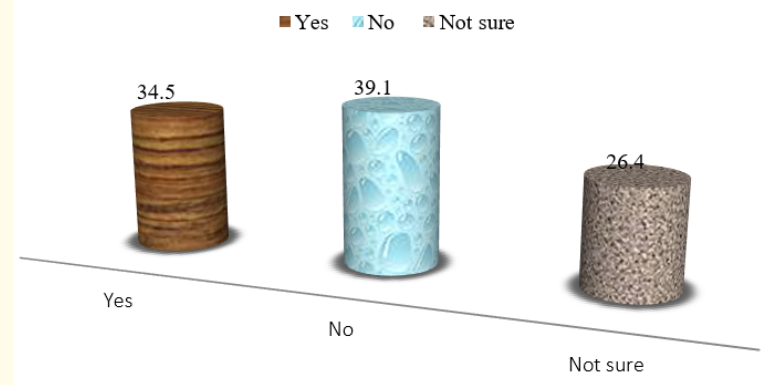

Figure 8: Knowledge about nutrition of the participants.

Know source of folic acid rich food of the participants

This table showed that yes participants were highest rate that was $49.4 \%(n=43)$. No participant second highest were rate that was $39.1 \%(n=34)$ and not sure participants were $11.5 \%(n=10)$ (Table 1).

\begin{tabular}{|c|c|c|c|}
\hline \multicolumn{3}{|c|}{ Know the source of some Folic acid rich } \\
foods & \\
\hline \multirow{4}{*}{ Valid } & Frequency & Percent \\
\cline { 2 - 4 } & Yes & 43 & 49.4 \\
\cline { 2 - 4 } & No & 34 & 39.1 \\
\cline { 2 - 4 } & Not sure & 10 & 11.5 \\
\cline { 2 - 4 } & Total & 87 & 100.0 \\
\hline
\end{tabular}

Table 1: Know source of folic acid rich food of the participants.
Know source of carbohydrate food of the participants

This table showed that yes participants were highest rate that was $52.9 \%(\mathrm{n}=46)$. No participant second highest were rate that was $26.4 \%(n=23)$ and not sure participants were $20.7 \%(n=18)$ (Table 2).

\begin{tabular}{|c|c|c|c|}
\hline \multicolumn{4}{|c|}{ Know the source of some Carbohydrate foods } \\
\hline & & Frequency & Percent \\
\hline \multirow{4}{*}{ Valid } & Yes & 46 & 52.9 \\
\hline & No & 23 & 26.4 \\
\hline & Not sure & 18 & 20.7 \\
\hline & Total & 87 & 100.0 \\
\hline
\end{tabular}

Table 2: Know source of carbohydrate food of the participants.

Know source of fatty food of the participants

This table showed that no participants were highest rate that was $43.7 \%(n=38)$. Not sure participant second highest were rate that was $29.9 \%(n=26)$ and yes participants were $26.4 \%(n=23)$ (Table 3).

\begin{tabular}{|c|c|c|c|}
\hline \multicolumn{4}{|c|}{ Know the source of some fatty foods? Good fat, bad fat } \\
\hline \multirow{2}{*}{ Valid } & Frequency & Percent \\
\cline { 2 - 4 } & Yes & 23 & 26.4 \\
\cline { 2 - 4 } & No & 38 & 43.7 \\
\cline { 2 - 4 } & Not sure & 26 & 29.9 \\
\cline { 2 - 4 } & Total & 87 & 100.0 \\
\hline
\end{tabular}

Table 3: Know the source of some fatty foods? Good fat, bad fat.

Know source of vitamin and minerals food

This table showed that no participants were highest rate that was $39.1 \%(n=34)$. Yes participant second highest were rate that was $33.3 \%(n=29)$ and not sure participants were $27.6 \%(n=24)$ (Table 4).

\begin{tabular}{|c|c|c|c|}
\hline \multicolumn{3}{|c|}{ Know the source of some vitamins and minerals foods } \\
\hline \multicolumn{1}{|c|}{} & Frequency & Percent \\
\hline \multirow{4}{*}{ Valid } & Yes & 29 & 33.3 \\
\cline { 2 - 4 } & No & 34 & 39.1 \\
\cline { 2 - 4 } & Not sure & 24 & 27.6 \\
\cline { 2 - 4 } & Total & 87 & 100.0 \\
\hline
\end{tabular}

Table 4: Know the source of some vitamins and minerals foods. 


\section{Safeties in food preparation}

This table showed that little moderate participants were highest rate that was $48.3 \%(n=42)$. Moderate participant second highest were rate that was $28.7 \%(\mathrm{n}=25)$ and mild participants were $23.0 \%(n=20)$ (Table 5).

\begin{tabular}{|c|c|c|c|}
\hline \multicolumn{4}{|c|}{ Safety in food preparation } \\
\hline \multirow{4}{*}{ Valid } & Frequency & Percent \\
\cline { 2 - 4 } & Mild & 20 & 23.0 \\
\cline { 2 - 4 } & Little Moderate & 42 & 48.3 \\
\cline { 2 - 4 } & Moderate & 25 & 28.7 \\
\cline { 2 - 4 } & Total & 87 & 100.0 \\
\hline
\end{tabular}

Table 5: Safeties in food preparation.

\section{FCS categories}

This figure showed that moderate participants were highest rate that was $35.6 \%(n=31)$. High participant second highest were rate that was $34.5 \%(n=30)$ and low participants were $29.9 \%(n$ = 26) (Figure 9).

\section{FCS categories}

$$
\text { - Low Moderate } \quad \text { High }
$$

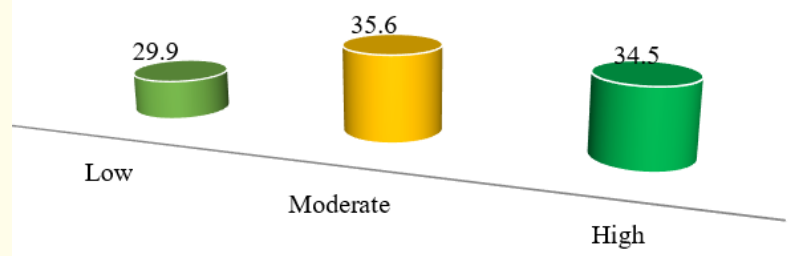

Figure 9: FCS categories.

Association between with FCS categories vs education status

\begin{tabular}{|c|c|c|}
\hline FCS categories and & Chi-Square & P-value \\
\hline education status & 7.27 & 0.507 \\
\hline
\end{tabular}

Table 6: Association between with FCS categories Vs education status.

This observed Chi-square value was 7.27 and $5 \%$ level of significant state chi-square was .90 which is less than the observed chi-square value. That means Null-hypothesis was rejected with FCS categories Vs education status and alternative hypothesis was accepted. So, the result was highly significant that indicate there was association between with FCS categories and education status.

Association between with FCS categories vs age of children's (ANOVA test)

\begin{tabular}{|l|c|c|c|c|c|}
\hline \multicolumn{7}{|c|}{ ANOVA } \\
\hline & $\begin{array}{c}\text { Sum of } \\
\text { Squares }\end{array}$ & df & $\begin{array}{c}\text { Mean } \\
\text { Square }\end{array}$ & F & Sig. \\
\hline $\begin{array}{l}\text { Between } \\
\text { Groups }\end{array}$ & 6.667 & 2 & 3.334 & 1.265 & .287 \\
\hline $\begin{array}{l}\text { Within } \\
\text { Groups }\end{array}$ & 221.287 & 84 & 2.634 & & \\
\hline Total & 227.954 & 86 & & & \\
\hline
\end{tabular}

Table 7: Association between with FCS categories Vs age of children's.

This observed between groups within sum square value was 6.667 and mean square 3.334 so the result was highly significant .287 that indicate there was association between with FCS categories and age of childrens.

\section{According to WFPO categories}

Main staples

This figure showed that 7 days intake of $100 \%(n=87)$ participants such food items rice, bread, cereals, potatoes (Figure 10).

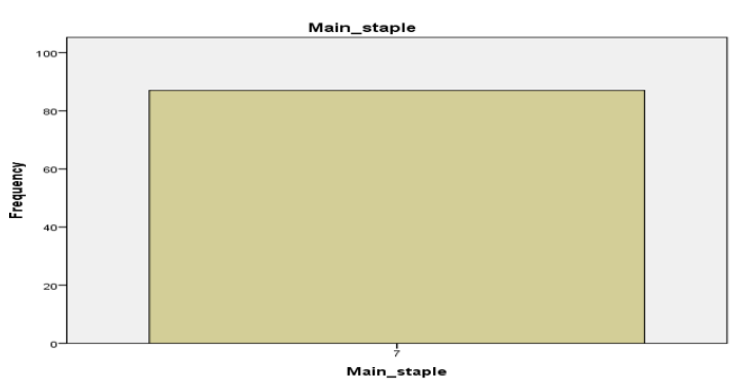

Figure 10: Main staple.

Vegetables

This figure showed that 7 days intake highest score were $89.7 \% \%(n=78)$ participants, 6 days intake were $1.1 \%(n=1), 5$ 
days intakes were $6.9 \%(n=6), 4$ days intake were $1.1 \%(n=1), 3$ days intake were $1.1 \%(\mathrm{n}=1)$ (Figure 11$)$.

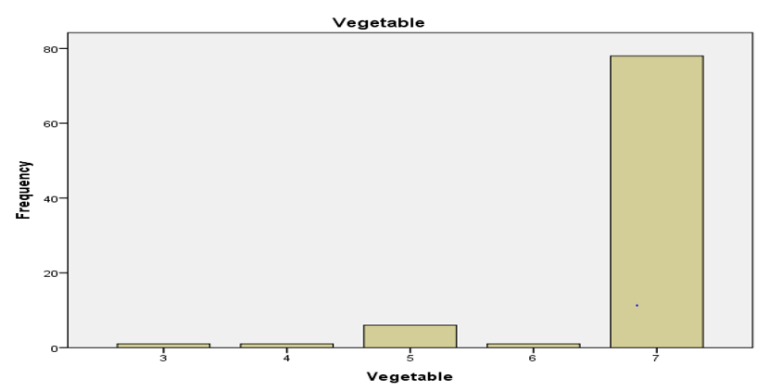

Figure 11: Vegetables.

\section{Fruits}

This figure showed that 7 days intake were $4.6 \% \%(n=4)$ participants, 6 days intake were 3.4\% ( $\mathrm{n}=3), 5$ days intakes were $16.1 \%(\mathrm{n}=14), 4$ days intake were $31 \%(\mathrm{n}=27), 3$ days intake were $23 \%(n=20) .2$ days intake were $10 \%(n=9), 1$ day intake $8 \%(n=7), 0$ days intake $3.4 \%$ were of $n=3$ (Figure 12 ).

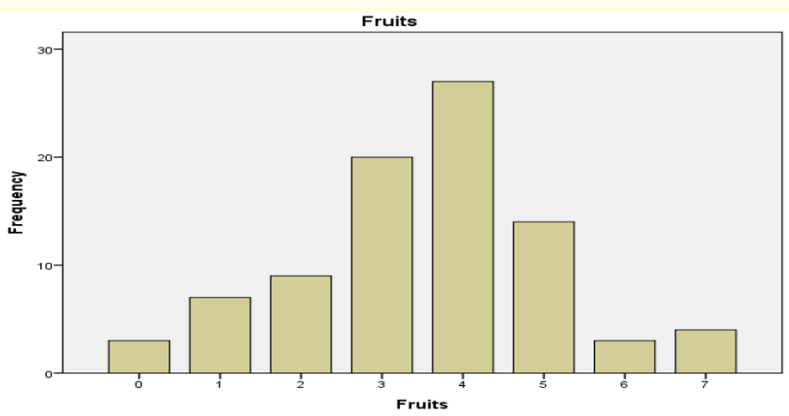

Figure 12: Fruits.

\section{Meat and fish}

This figure showed that 7 days intake of $100 \%(n=87)$ participants such food items beef, goat, pork, eggs, fish (Figure 13).

\section{Milk and milk products}

This figure showed that 7 days intake were $2.3 \%(\mathrm{n}=2)$ participants, 6 days intake were $13.8 \%(n=12), 5$ days intakes were $23 \%$ $(\mathrm{n}=20), 4$ days intake were $36.8 \%(\mathrm{n}=32), 3$ days intake were $20.7 \%(n=18) .2$ days intake were $3.4 \%(n=3)$ (Figure 14$)$.

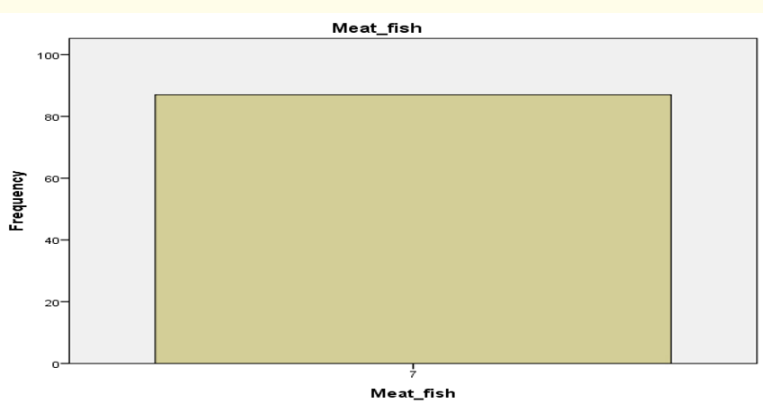

Figure 13: Meat and fish.

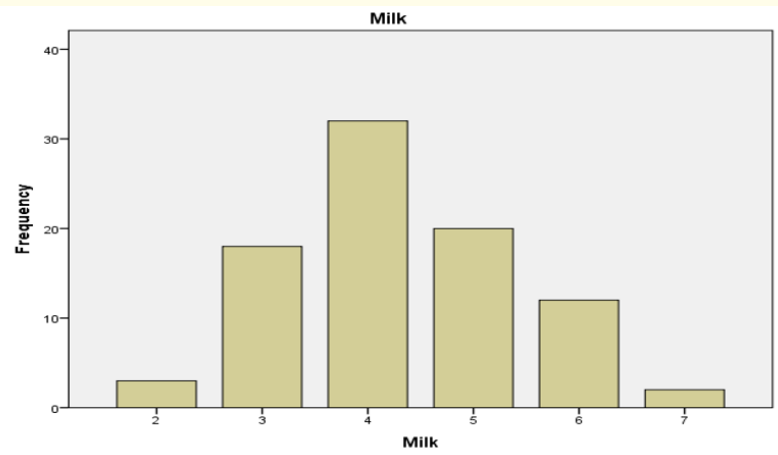

Figure 14: Milk and milk products.

Oil

This figure showed that 7 days intake were $1.1 \%(n=1)$ participants, 6 days intake were $16.1 \%(n=14), 5$ days intakes were $20.7 \%(\mathrm{n}=18), 4$ days intake were $27.6 \%(\mathrm{n}=24), 3$ days intake were $18.4 \%(n=16) .2$ days intake were $10.3 \%(n=9) .1$ day intake were $2.3 \%(n=2) .0$ days $3.4 \%(n=3)$ (Figure 15$)$.

\section{Discussion}

Cross-sectional type of quantitative study design was in our country children with disabilities are more likely to suffer from nutritional deficiencies than others, for reasons including low social status, poverty; and lack of proper nutritional knowledge. Total number of accomplices was eighty seven for quantitative study. To assess the nutritional status and nutritional related knowledge of children or their caregiver of CWD in Dhaka city. To assess the anthropometric measurement by BMI, WAZ, HAZ of the participants, to assess the nutrition related knowledge of the children or their 


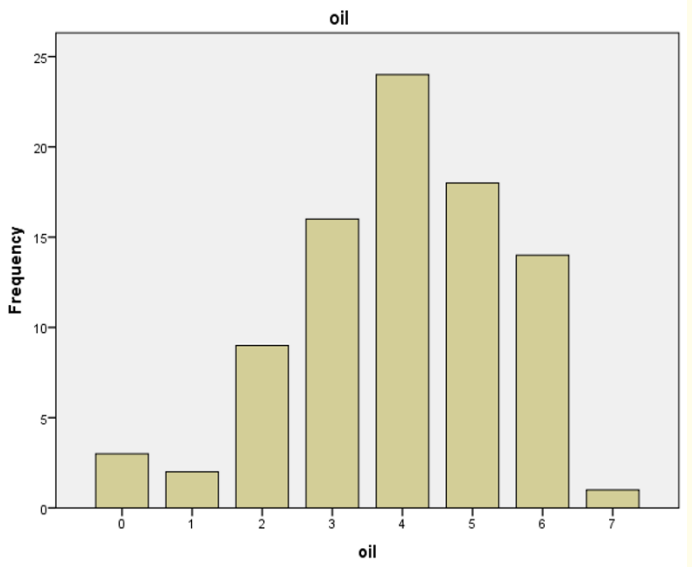

Figure 15: Oil. caregivers of the participants, to appraise the food frequency pattern of the participants. To find out socio-demographic (age, gender of caregivers, educational status of caregivers, family type, types of house, religious, family income monthly) uniqueness of CWD living in Dhaka city. The study found that mean age of the participant was 9.98 (SD \pm 1.62 ) years and most of the participants were above 5 years. The youngest participants in this study were 7 years old and oldest participants were 12 years old. Ardic., et al. (2003) performed a cross-sectional study for these purpose 78 patients (mean age $57.8 \pm 11.9$ years, 55 women and 23 men) were randomly selected for inclusion in the study. Another result has been reported by Chacon., et al. (2004) who concluded that the mean age was \pm 64.9 and their age range was $41-86$ years. So above two studies, mean age was not similar to this study. So, this indicated that nutrition related Knowledge had relation the participants in this study earlier than others study. In this study, this study showed that male caregivers participants were highest rate that was $58.6 \%(n=51)$. Female caregivers participant were rate that was $41.4 \%(n=36)$ with males attended more than females, and no predilection for race (Arshad., et al. 2015) and other study Adriana Angarita-Fonseca and Víctor M Herrera-Galindo, 2016. In this study showed $>10000$ BDT range participants were highest rate that was $62.1 \%(\mathrm{n}=54) .7000-10000$ BDT participant were second highest rate that was $19.5 \%(n=17) .5000-7000$ BDT range were $13.8 \%(n=12)$ and $>5000$ BDT range were $4.6 \%(n=4)$. Primary passed participants were highest rate that was $34.5 \%$ ( $\mathrm{n}=$ 30 ). More degree passed participant were second highest rate that was $31 \%(n=27)$. HSC Participants were 19.5\% ( $n=17)$, secondary participants were $11.5 \%(n=10)$ and none participants were
3.4\% ( $\mathrm{n}=3)$. Another result has been Birhanu Gizaw, 2018 showed his study education level highest primary level and male participants highest ratio. The aim of this study was to assess the nutrition related knowledge of the children or their caregivers of the respondents. According to our findings, knowledge about nutrition of the participants showed that no participants were highest rate that was $39.1 \%(n=34)$. Yes participant second highest were rate that was $34.5 \%(n=30)$ and not sure participants were $26.4 \%$ (n =23). Knowledge about nutrition components of the participants. This study showed that yes participants were highest rate that was $41.4 \%(\mathrm{n}=36)$. No participant second highest were rate that was $29.9 \%(n=26)$ and not sure participants were $28.7 \%(n=25)$. know source of folic acid rich food of the participants This study showed that yes participants were highest rate that was $49.4 \%$ (n = 43). No participant second highest were rate that was $39.1 \%$ (n $=34$ ) and not sure participants were $11.5 \%(n=10)$. Know source of carbohydrate food of the participants this study showed that yes participants were highest rate that was $52.9 \%(n=46)$. No participant second highest were rate that was $26.4 \%(n=23)$ and not sure participants were $20.7 \%(n=18)$. Know source of fatty food of the participants this study showed that no participants were highest rate that was $43.7 \%(n=38)$. Not sure participant second highest were rate that was $29.9 \%(n=26)$ and yes participants were $26.4 \%$ ( $\mathrm{n}=23$ ). Know source of vitamin and minerals food this study showed that no participants were highest rate that was 39.1\% (n = 34). Yes participant second highest were rate that was $33.3 \%$ ( $n=$ $29)$ and not sure participants were $27.6 \%(n=24)$. Safeties in food preparation this study showed that little moderate participants were highest rate that was $48.3 \%(n=42)$. Moderate participant second highest were rate that was $28.7 \%(n=25)$ and mild participants were $23.0 \%(n=20)$. This study showed that no participants were highest rate that was $39.1 \%(n=34)$. Yes participant second highest were rate that was $34.5 \%(n=30)$ and not sure participants were $26.4 \%(n=23)$. The results showed that most of FCS categories this showed that moderate participants were highest rate that was $35.6 \%(n=31)$. High participant second highest were rate that was $34.5 \%(\mathrm{n}=30)$ and low participants were $29.9 \%(\mathrm{n}$ =26). Main staples this study showed that 7 days intake of $100 \%$ ( $n=87$ ) participants such food items rice, bread, cereals, potatoes. Vegetables this study showed that 7 days intake highest score were $89.7 \% \%(n=78)$ participants, 6 days intake were $1.1 \%(n=1), 5$ days intakes were $6.9 \%(n=6), 4$ days intake were $1.1 \%(n=1), 3$ days intake were $1.1 \%(n=1)$. Fruits this study showed that 7 days intake were $4.6 \% \%(n=4)$ participants, 6 days intake were $3.4 \%$ $(n=3), 5$ days intakes were $16.1 \%(n=14), 4$ days intake were 
$31 \%(\mathrm{n}=27), 3$ days intake were $23 \%(\mathrm{n}=20) .2$ days intake were $10 \%(\mathrm{n}=9), 1$ day intake $8 \%(\mathrm{n}=7), 0$ days intake $3.4 \%$ were of $\mathrm{n}=3$. Meat and fish this study showed that 7 days intake of $100 \%$ ( $n=87$ ) participants such food items beef, goat, pork, eggs, fish. Milk and milk products this study showed that 7 days intake were $2.3 \%(n=2)$ participants, 6 days intake were $13.8 \%(n=12), 5$ days intakes were $23 \%(n=20), 4$ days intake were $36.8 \%(n=32)$, 3 days intake were $20.7 \%(\mathrm{n}=18) .2$ days intake were $3.4 \%(\mathrm{n}=$ 3). Oil this study showed that 7 days intake were $1.1 \%(n=1)$ participants, 6 days intake were 16.1\% $(n=14), 5$ days intakes were $20.7 \%(\mathrm{n}=18), 4$ days intake were $27.6 \%(\mathrm{n}=24), 3$ days intake were $18.4 \%(n=16) .2$ days intake were $10.3 \%(n=9) .1$ day intake were $2.3 \%(n=2) .0$ days $3.4 \%(n=3)$.

\section{Conclusion}

Normal nutritional needs remain throughout the life. Good nutrition generally can improve the spirit and quality of life, can speed recovery from illness and prolong life. Teenage is a unique interventions point of life cycle. In a developing country like Bangladesh it could be observed that children with Down's syndrome were at risk of being severely impaired nutritional status, while children with CP, epilepsy, speech delay \& vertigo were at risk of being moderately impaired nutritional status and children with ADHD were at risk of being overweight or obese. Children with autism had mostly normal nutritional status, while children of CP with epilepsy were at risk of being mildly impaired nutritional status. Beside low monthly income family with low aged child was somewhere related with nutrition status. Overall, nutritional statuses of the child with disability were below acceptance. Per capita dietary intake was poor and imbalanced containing very low amount of micronutrients leading to malnutrition. Nutrition intervention program needs to be administered especially targeting CWD.

\section{Acknowledgements}

The authors are so grateful to all participating health care professionals for their valuable time and kind help.

\section{Funding Support}

This article had academic research paper. There is no financial support.

\section{Conflict of Interest}

None.

\section{Author's Contributions}

Both authors made substantial contribution to the conception, design, analysis and interpretation of data.

\section{Bibliography}

1. Akhter Neyamul and Farida Yasmin Sondhya. "Nutritional status of adolescents in Bangladesh: Comparison of severe thinness status of a low-income family's adolescents between urban and rural Bangladesh". Journal of Education and Health Promotion 2 (2013): 27.

2. Amil-Dias Jorge., et al. "Surgical management of Crohn disease in children: guidelines from the Pediatric IBD Porto Group of ESPGHAN". Journal of Pediatric Gastroenterology and Nutrition 64.5 (2017): 818-835.

3. Bangladesh Rehabilitation Council Act (2018).

4. Cole Tim J., et al. "Body mass index cut offs to define thinness in children and adolescents: international survey". BMJ 335.7612 (2007): 194.

5. Kalhan M., et al. "Nutritional status of adolescent girls of rural Haryana". Internet Journal of Epidemiology 8.1 (2010).

6. Lin Jin-Ding, et al. "Physical activity and its determinants among adolescents with intellectual disabilities". Research in Developmental Disabilities 31.1 (2010): 263-269.

7. Marchand Valerie and Kathleen J Motil. "Nutrition support for neurologically impaired children: a clinical report of the North American Society for Pediatric Gastroenterology, Hepatology, and Nutrition". Journal of Pediatric Gastroenterology and Nutrition 43.1 (2006): 123-135.

8. Mikulovic Jacques., et al. "Prevalence of overweight in adolescents with intellectual deficiency. Differences in socio-educative context, physical activity and dietary habits". Appetite 56.2 (2011): 403-407.

9. Pan Cheng-Chen. "Examination of associations of physical selfconcept of athletes with intellectual disabilities". Diss (2016).

10. Prentice Ann., et al. "Symposium on 'Nutrition and health in children and adolescents' Session 1: Nutrition in growth and development Nutrition and bone growth and development: A meeting of the Nutrition Society hosted by the Irish Section was held on 14-16 June 2006 at University College Cork, Cork, Republic of Ireland". Proceedings of the Nutrition Society 65.4 (2006): 348-360.

11. Roy Krishna. "Nutritional Status, Dietary Intake And Onset of Menarche Among Socio-economically Backward Adolescent Scheduled Tribe Female Subjects of Birbhum District Of West 
Bengal". International Bilingual Journal of Culture, Anthropology and Linguistics 1.1 (2019): 21-34.

12. San Juan, PM Fernández. "Dietary habits and nutritional status of school aged children in Spain". Nutrition Hospital Aria 21.3 (2006): 374-378.

13. Slevin Eamonn., et al. "Obesity and overweight in intellectual and non-intellectually disabled children". Journal of Intellectual Disability Research 58.3 (2014): 211-220.

14. Smith, Harry., et al. "Exploring appropriate socio-technical arrangements for the co-production of landslide risk management strategies in informal neighborhoods in Colombia and Brazil". International Journal of Urban Sustainable Development (2021): 1-22.

15. Tilman David and Michael Clark. "Global diets link environmental sustainability and human health". Nature 515.7528 (2014): 518-522.

16. Uwayezu Donat., et al. "Conflict between Science and Superstition in Medical and Dental Practices". (2021).

17. Velez Juan C., et al. "Nutritional status and obesity in children and young adults with disabilities in Punta Arenas, Patagonia, Chile". International Journal of Rehabilitation Research 31.4 (2008): 305-313.

18. Wanden-Berghe Carmina, et al. "Home enteral nutrition in Spain: NADYA registry 2011-2012". Nutrition Hospital Aria (2014).

19. World Health Organization. "Department of maternal, newborn, child and adolescent health (MCA): progress report 2014-15". (2016).

20. World Health Organization. "World report on disability 2011". World Health Organization (2011).

Volume 5 Issue 7 July 2021

(C) All rights are reserved by Md Harun-Or-Rashid., et al. 